\title{
Synergistic antiviral effects against SARS-CoV-2 by plant-based molecules
}

\author{
Ashish Prasad ${ }^{1} \cdot$ Mehanathan Muthamilarasan $^{2} \cdot$ Manoj Prasad $^{1}[0$
}

Received: 14 May 2020 / Accepted: 12 June 2020 / Published online: 19 June 2020

c) Springer-Verlag GmbH Germany, part of Springer Nature 2020

\begin{abstract}
The exponential spread of Severe acute respiratory syndrome coronavirus 2 (SARS-CoV-2) emphasizes the immediate need for effective antiviral drugs and vaccines that could control and prevent the spread of this pandemic. Several new and repurposed drugs are being tested for their effectiveness in the treatment regime, and the development of vaccines is underway. The availability of genome sequence information of the virus and the identification of potential targets to neutralize and eradicate the infection have enabled the search for novel as well as existing molecules to perform the desired function. However, the application of plants in the development of potential biomolecules, such as antibiotics and vaccines, is limited. Traditional medicines involving plant-based formulations have proven successful in boosting immunity and providing tolerance to virus infections. Still, in-depth studies are not available to explore the bioactive compounds of plant origin and their mechanism of action. Given this, the current opinion article conveys our thoughts and perspectives on the promising usage of plant-based biomolecules in circumventing SARS-CoV-2, and how these molecules can work synergistically with other potential drugs for treating SARS-CoV-2.
\end{abstract}

Keywords SARS-CoV-2 Plant-based drugs $\cdot$ Antiviral biomolecules $\cdot$ Plant-based vaccines $\cdot$ Traditional medicine $\cdot$ Synergistic effect

\section{Repurposing of existing antiviral drugs to treat SARS-CoV-2}

Severe acute respiratory syndrome coronavirus 2 (SARS$\mathrm{CoV}-2$ ) has spread at a tremendous rate, and there is an immediate need for vaccines to mass immunize the human race and antiviral drugs for the treatment of infected individuals. Given the statement of World Health Organization that there is no effective vaccine or antiviral drug available to prevent or treat SARS-CoV-2, a rampant search is

Communicated by Neal Stewart.

Ashish Prasad and Mehanathan Muthamilarasan have contributed equally.

Manoj Prasad

manoj_prasad@nipgr.ac.in

1 National Institute of Plant Genome Research, Aruna Asaf Ali Marg, New Delhi 110067, India

2 Department of Plant Sciences, School of Life Sciences, University of Hyderabad, Hyderabad, Telangana 500046, India being conducted to identify new antiviral molecules-as evidenced by the increasing reports published in journals as well as preprint servers. Studies on the use of available vaccines, including BCG (Bacille Calmette-Guérin vaccine), to develop immunity against this virus are also underway. Specific vaccines against SARS-CoV-2 are also being developed in many laboratories across the world. Curevac's mRNA-based vaccine is in the pre-clinical phase. Vaccine utilizing S-glycoprotein as an antigen is being developed by the University of Queensland, Baylor College of Medicine, Novavax, iBio, ExpresS2ion, and Sichuan Clover Biopharmaceuticals. Applied DNA Sciences and Inovio are attempting to engineer DNA vaccines, while Serum Institute of India is involved in the development of a live attenuated vaccine against SARS-CoV-2 (Amanat and Krammer 2020). Irrespective of this, several existing antiviral drugs need to be tested for their effect on SARS-CoV-2, and some are even being used currently ( $\mathrm{Li}$ and De Clercq 2020). This includes the use of ritonavir and lopinavir (HIV protease inhibitors; Chen et al. 2020); azvudine (reverse transcriptase inhibitor; Harrison 2020); and ribavirin, favipiravir, and remdesivir (nucleoside analogs; Wang et al. 2020). Drugs previously 
approved by the FDA for other diseases are also being repurposed. For example, inhibitors of endosomal acidification fusion (chloroquine and hydroxychloroquine) and redox enzymes (auranofin) used to treat rheumatoid arthritis have also shown promising results against SARS-CoV-2 (Rothan et al. 2020; Wang et al. 2020). Xing et al. (2020) screened the host gene expression profiles of samples infected by SARS- and MERS-CoV to identify the gene expression signature of the viruses, and ten existing drugs targeting these signatures were tested for their efficacy in the Vero E6 cell line. Out of these, four drugs showed effective inhibition of virus infection-induced cytopathic effect; however, further studies awaited on this aspect are necessary to evaluate the practicality of the findings.

In this scenario, the plant kingdom remains largely unexplored that could possess several bioactive molecules of therapeutic importance. A recent review by Yang et al. (2020) underlines the role of traditional Chinese medicine in treating SARS-CoV-2 patients. However, no such comprehensive studies are available in countries that have a strong background in using medicinal plants for treating broad-spectrum diseases since ancient times. For instance, India predominantly relied on plant-based medications under different domain names like Ayurveda, Siddha, Unani, etc. Though the advent of allopathic medicines has cornered the prevalence of plant-based treatments, the current pandemic emphasizes the need for revisiting those plants and studying them using advanced tools and approaches. Technological interventions are the need-of-the-time to dissect the medicinal value of plants for identifying suitable phytocompounds that could serve as potential molecules in treating SARS$\mathrm{CoV}-2$. In this context, the article sheds light on the potential of plants and plant-based drugs for their use in treating COVID-19. We enumerate the plant-based medicines being used for treating different viral infections and categorically explain the importance of identifying novel biomolecules from plants that could be used for therapeutic applications. We underline that such biomolecules can work in synergy with synthetic drugs to provide enhanced antiviral effects.

\section{Traditional plant-based medicine and synergistic studies thereof}

China has an excellent track record of using traditional plantbased formulations in successfully treating SARS coronavirus (SARS-CoV) in the Guangdong Province from late 2002 through mid-2003 (Chen and Nakamura 2004; Zhong 2004; Lau et al. 2005). Though precise information about the nature and composition of those plants and their mode of actions are not available, secondary metabolites draw attention as they possess bioactive properties (O'Connor 2015). One such successful example is quinine, an alkaloid obtained from the bark of Cinchona officinalis and has been used in the treatment of malaria since the 1960s (Achan et al. 2011). Chloroquine (Cq) and hydroxychloroquine (Hcq) are structural analogs of quinine. In SARS-CoV-2, Hcq in combination with azithromycin, is found to be more effective in reducing the viral load (Gautreta et al. 2020). Similarly, glycyrrhizin, a saponin isolated from Glycyrrhiza glabra roots, is reported to be effective against SARS-CoV by inhibiting viral replication (Cinatl et al. 2003). Considering the structural similarities and comparable modes of replication between SARS-CoV and SARS-CoV-2, glycyrrhizin might also be effective in treating the current pandemic. Water extract of Houttuynia cordata has antiviral activity against SARS-CoV due to its inhibitory effect on 3C-like protease (3CLpro) and RNA-dependent RNA polymerase (RdRp) of the virus. Myricetin, a flavonoid obtained from Myrica rubra, and Scutellarein, a flavone obtained from Scutettaria baicalensis and Asplenium belangeri are known to inhibit the ATPase activity of SARS-CoV helicase nsP13 (Yu et al. 2020). Flavones such as amentoflavone, quercetin, luteolin and apigenin obtained from Torreya nucifera have also been proven to inhibit 3CLpro function (Ryu et al. 2010). Lycorine, an alkaloid extracted from Lycoris radiata, has antiviral activity against Poliomyelitis virus and Herpes simplex virus, and is also effective against SARS-CoV $(\mathrm{Li}$ et al. 2005). Emodin, sinigrin and hesperetin extracted from Isatis indigotica have also shown 3CLpro inhibition (Lin et al. 2005). In addition, lectins of plants could be potential inhibitors of viruses. A study by Keyaerts et al. (2007) has screened 33 lectins isolated from different plant species for their activity against both SARS-CoV and Feline coronavirus ( $\mathrm{FCoV})$. They identified mannose-binding lectin to possess a robust anti-coronaviral activity by targeting the entry as well as the release of virus particles (Keyaerts et al. 2007). Another lectin, agglutinin isolated from Galanthus nivalis, was able to effectively act against FCoV when administered in combination with nelfinavir, a synthetic drug (Hsieh et al. 2010). This underlines the need for studying the combined effect of plant-based compounds and synthetic molecules to circumvent the viral load in the host system. However, minimal efforts were invested in this direction to study the synergistic antiviral effect of biomolecules and drugs.

Recently, a natural stilbene derivative named resveratrol (trans-3, 5, 4'-trihydroxystilbene) present abundantly in Vitis vinifera, Polygonum cuspidatum, and Vaccinium macrocarpon showed inhibition of MERS-CoV infection (Lin et al. 2017). Table 1 summarizes several plant-based metabolites reported to have antiviral properties. The data collectively show that several metabolites were identified and characterized for their antiviral roles, and there is a lacuna in using this information to proceed with subsequent studies for translating into active biotherapeutics. Besides, several potential plant species anticipate even preliminary studies 
Table 1 A few plant-based biomolecules showing antiviral activity against coronaviruses

\begin{tabular}{|c|c|c|c|c|}
\hline Plant product & Source & Virus & Mode of action & References \\
\hline Mannose-binding lectins & $\begin{array}{l}\text { Several plant species were } \\
\text { used in the study }\end{array}$ & $\begin{array}{l}\text { SARS-Cov and Feline infec- } \\
\text { tious peritonitis virus }\end{array}$ & $\begin{array}{l}\text { Inhibitory effect on glycans } \\
\text { present in S-glycoprotein } \\
\text { of the viruses }\end{array}$ & (Keyaerts et al. 2007) \\
\hline $\begin{array}{l}\text { Water extract of tender } \\
\text { leaves }\end{array}$ & Toona sinensis & SARS-CoV and HCoV 229E & $\begin{array}{l}\text { Inhibition of viral replica- } \\
\text { tion }\end{array}$ & (Chen et al. 2008) \\
\hline Saikosaponins & $\begin{array}{l}\text { Bupleurum sp, Heteromor- } \\
\text { pha sp and Scrophularia } \\
\text { scorodonia }\end{array}$ & HCoV 229E & $\begin{array}{l}\text { Penetration and adsorption } \\
\text { of virus on host surface is } \\
\text { hampered }\end{array}$ & (Cheng et al. 2006) \\
\hline Emodin & Rheum sp and Polygonum sp & SARS-CoV & $\begin{array}{l}\text { ACE2 and S-glycoprotein } \\
\text { interaction is blocked }\end{array}$ & (Ho et al. 2007) \\
\hline Aescin, reserpine & $\begin{array}{l}\text { Aesculus hippocastanum and } \\
\text { Rauvolfia serpentina }\end{array}$ & SARS-CoV & $\begin{array}{l}\text { Inhibition of viral replica- } \\
\text { tion }\end{array}$ & (Wu et al. 2004) \\
\hline $\begin{array}{l}\text { Phenanthroindolizidines and } \\
\text { Phenanthroquinolizidines }\end{array}$ & $\begin{array}{l}\text { Asclepiadaceae and } \\
\text { Moraceae plant families }\end{array}$ & SARS-CoV & $\begin{array}{l}\text { Inhibition of viral replica- } \\
\text { tion }\end{array}$ & (Yang et al. 2010) \\
\hline Ethanolic extract & Euphorbia neriifolia & SARS-CoV & Antiviral activity & (Chang et al. 2012) \\
\hline $\begin{array}{l}\text { Tetra-O-galloyl- } \beta \text {-D-glucose } \\
\text { and luteolin }\end{array}$ & $\begin{array}{l}\text { Euphorbia jolkinin and } \\
\text { Reseda luteola }\end{array}$ & SARS-CoV & Antiviral activity & (Yi et al. 2004) \\
\hline Quercetin derivatives & $\begin{array}{l}\text { Malus sp, Allium sp, Camel- } \\
\quad \text { lia sp, etc }\end{array}$ & SARS-CoV & Antiviral activity & (Park et al. 2012) \\
\hline
\end{tabular}

to be conducted. The traditional Indian medicine system has been classified into Ayurvedic, Siddha and Unani (nonnative), and all the three systems are based on administering plant-based formulations to patients (Thileepan and Prasad 2018). In case of SARS-CoV-2, the Ministry of AYUSH (Ayurveda, Yoga and Naturopathy, Unani, Siddha and Homoeopathy), Government of India, has recommended a formulation composed of 15 plants, namely, Zingiber officinale, Piper longum, Syzygium aromaticum, Tragia involucrata, Anacyclus pyrethrum, Hygrophilla auriculata, Terminalia chebula, Adhatoda vasica, Plectranthus amboinicus, Saussurea costus, Tinospora cordifolia, Clerodendrum serratum, Andrographis paniculate, Sida acuta, and Cyperus rotundus (6.6\% each; PIB 2020). Though Sivaraman and Pradeep (2020) and Vellingiri et al. (2020) had underlined the positive side of this plant-based concoction that keeps the infection levels at bay, no extensive studies were performed neither to identify the chemical composition nor the mode of action in these plants. In this direction, Max Planck Institute of Colloids and Interfaces (Germany) is collaborating with ArtemiLife Inc. (USA) to explore the effect of artemisinin derivatives isolated from Artemisia annua against SARS-CoV-2 (MPIKG 2020).

\section{Bio-farming: towards the development of plant-based vaccines and active metabolites}

Plant biotechnology has advanced at a tremendous pace, and cloning and expression of proteins in plants are now a routine task in the laboratories across the world. This eases the production of recombinant biomolecules like vaccines, antibodies, enzymes, and hormones in plant systems through bio-farming (Rosales-Mendoza 2020). Transgenic as well as transient systems have been optimised for procuring high yields of recombinant molecules. Such plant-based recombinant biomolecules are free from human and animal pathogens. The problem of post-translational modifications in using bacteria as a host is also overcome while using the plant system (Takeyama et al. 2015). It also minimizes other risks like, for example, disease transmission and immunogenicity of collagen extracted from the animal system was avoided by adopting plant produced collagen (Shoseyov et al. 2013). Human type 1 collagen, which is produced in Nicotiana benthamiana has already been commercialized. Several vaccines for viruses like Influenza virus (H1N1, H5N1 and H7N9), Norovirus, Hepatitis B virus and Rabies virus produced in plants are under clinical trials (Takeyama et al. 2015). In case of coronavirus, literature shows the production of vaccines and antibodies from plants for prevention and treatment. Leaf extracts of Arabidopsis thaliana engineered to express N-terminal of S-glycoprotein of swine-transmissible gastroenteritis coronavirus (STGC) showed immunogenic activity against the virus. Antibodies produced in mice neutralized the virus infectivity (Gómez et al. 1998). In another study, the same protein was expressed 
in Solanum tuberosum, and mice fed on transgenic potato tubers displayed immunogenic response and development of antibodies (Gómez et al. 2000). The result also highlights the immense potential of plant-based food as a source of antigens for eliciting an immunogenic response in animal systems. S-glycoprotein of SARS-CoV has been stably expressed in $N$. benthamiana and Lactuca sativa and has potential as an oral vaccine ( $\mathrm{Li}$ et al. 2006). Another example with food as a potential source of antigen has been shown in case of SARS-CoV. Fruits of Solanum lycopersicum transformed with S-glycoprotein of SARS-CoV could induce the production of virus-specific Immunoglobin-A (IgA) in mice (Pogrebnyak et al. 2005). Medicago Inc. (Canada) and iBio Inc. (USA) have already started working towards the development of plant-made vaccines for SARS-CoV-2. Both the companies are making viruslike particle (VLP)-based vaccines (Rosales-Mendoza 2020). Kentucky BioProcessing (KBP, USA) has commenced the development of a tobacco-based vaccine, which is reported to be in the pre-clinical testing stage. The vaccine is claimed to be stable under room temperature and has the potential to deliver an effective immune response in a single dose (BAT 2020).

Sequencing of SARS-CoV-2 genomes would also enable epitope mapping that could be targeted for designing and developing an efficacious vaccine against SARS-CoV-2. As plant-based vaccines provide the ease of administration and monitoring, developing such a vaccine for SARS-CoV-2 would assist in executing mass immunization drives. Also, the feasibilities associated with transport, storage and monitoring are higher in the case of plant-based vaccines. This altogether accentuates the importance of plant-based drugs in treating COVID-19 patients. Though plants are a source of bioactive metabolites having antiviral properties, these compounds might be present in low concentrations and incur difficulties during isolation from the source. Thus, biotechnology comes to the rescue for producing these compounds through in vitro culturing techniques like cell culture, and the intervention of metabolic engineering can aid in higher recovery of active metabolites from the cells (Kayser 2018). Several important metabolites like paclitaxel (Khosroushahi et al. 2006) and artemisinin (Baldi and Dixit 2008) have been upscaled through bioengineering approaches. Thus, metabolite engineering has immense potential for the production of antiviral compounds against SARS-CoV-2 as well as other pathogens in plants and other heterologous systems.

\section{Conclusion}

The ongoing viral pandemic is a perfect example of how globalization and travel accessibility around the world can lead to the rapid spread of communicable diseases. Thus, cost-effective therapeutics must be developed to control the present outbreak as well as to prepare for future occurrences. Considering the vast number of plant-based compounds at our disposal and their potential in inhibiting coronavirus proteins, these compounds should be tested against SARSCoV-2 (Fig. 1) and evaluated with design-build-test-learn cycle to assess their effectiveness and side effects. Bio-farming is well established for the expression of recombinant molecules in plants, and several studies have already shown the effectiveness of plant-based vaccines. Pandemics of the ongoing scale cause a massive loss in terms of human lives and economy, and such catastrophe cannot be afforded in the future; thus, we require low-cost vaccines that can be used for large-scale immunization programmes. Plant-based vaccine production is now well established, and some have also entered clinical trials. Policy support and collaborations between academic institutions and industries (purchasing power parity) are important for such ventures and to facilitate large-scale production of plant-based antiviral molecules and vaccines. Particularly, the synergistic effect of these molecules coupled with synthetic drugs should be mandatorily tested as studies have shown higher efficiency of this combination in reducing the viral load. Such work will not only prove effective against the ongoing pandemic but also serve as a roadmap for any future encounters with different viral strains. 


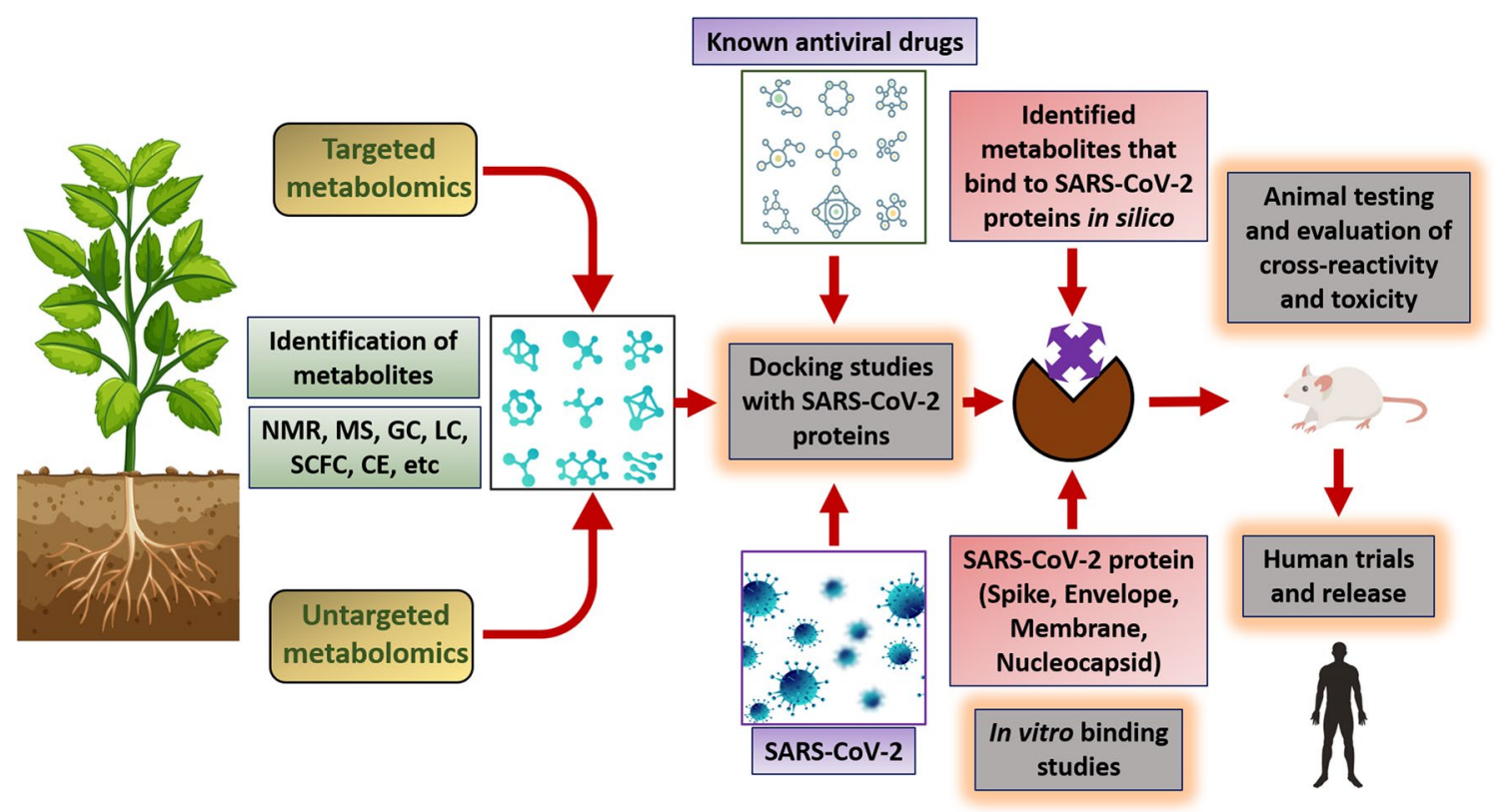

Fig. 1 A possible route of identification of antiviral drugs against SARS-CoV-2. Targeted and untargeted metabolomics approach may be utilized for identification of plant metabolites. The identified metabolites can be utilized in docking studies to check their interaction with SARS-CoV-2 proteins. Metabolites having in silico binding potential can then be validated by in vitro techniques. These can then

Acknowledgements Authors' work in this area is supported by J.C. Bose National Fellowship Grant of Department of Science and Technology, Government of India (File no.: JCB/2018/000001). A.P. acknowledges the Council for Scientific and Industrial Research, Govt. of India for research fellowship. Authors are thankful to DBT-eLibrary Consortium (DeLCON) for providing access to e-resources.

Author contribution statement MP conceived the idea, AP wrote the first draft, and MM improved the manuscript and provided revisions to the manuscript. All the authors have read and approved the final version of the manuscript.

\section{Compliance with ethical standards}

Conflict of interest The authors declare no conflict of interest.

\section{References}

Achan J, Talisuna AO, Erhart A et al (2011) Quinine, an old antimalarial drug in a modern world: role in the treatment of malaria. Malar J 10:144. https://doi.org/10.1186/1475-2875-10-144

Amanat F, Krammer F (2020) SARS-CoV-2 vaccines: status report. Immunity 52:583-589. https://doi.org/10.1016/j.immun i. 2020.03 .007

Baldi A, Dixit VK (2008) Yield enhancement strategies for artemisinin production by suspension cultures of Artemisia annиa. Bioresour Technol 99:4609-4614. https://doi.org/10.1016/j.biort ech.2007.06.061 be tested for their antiviral potential against SARS-CoV-2 in animal models followed by clinical trials. $N M R$ nuclear magnetic resonance, $M S$ mass spectrometry, $G C$ gas chromatography, $L C$ liquid chromatography, $S C F C$ supercritical fluid chromatography, $C E$ capillary electrophoresis. Image designed using Freepik

BAT (2020) British American tobacco p.l.c. press release. https:// www.bat.com/group/sites/UK_9D9KCY.nsf/vwPagesWebLive/ DOBN8QNL. Accessed 10 May 2020

Chang FR, Yen CT, Ei-Shazly M et al (2012) Anti-human coronavirus (anti-HCoV) triterpenoids from the leaves of Euphorbia neriifolia. Nat Prod Commun 7:1415-1417. https://doi. org/10.1177/1934578x1200701103

Chen Z, Nakamura T (2004) Statistical evidence for the usefulness of Chinese medicine in the treatment of SARS. Phyther Res 18:592-594. https://doi.org/10.1002/ptr.1485

Chen CJ, Michaelis M, Hsu HK et al (2008) Toona sinensis Roem tender leaf extract inhibits SARS coronavirus replication. J Ethnopharmacol 120:108-111. https://doi.org/10.1016/j. jep.2008.07.048

Chen N, Zhou M, Dong X et al (2020) Epidemiological and clinical characteristics of 99 cases of 2019 novel coronavirus pneumonia in Wuhan, China: a descriptive study. Lancet 395:507-513. https://doi.org/10.1016/S0140-6736(20)30211-7

Cheng PW, Ng LT, Chiang LC, Lin CC (2006) Antiviral effects of saikosaponins on human coronavirus $229 \mathrm{E}$ in vitro. Clin Exp Pharmacol Physiol 33:612-616. https://doi.org/10.111 1/j.1440-1681.2006.04415.x

Cinatl J, Morgenstern B, Bauer G et al (2003) Glycyrrhizin, an active component of liquorice roots, and replication of SARSassociated coronavirus. Lancet 361:2045-2046. https://doi. org/10.1016/S0140-6736(03)13615-X

Gautreta P, Lagiera J-C, Parola P et al (2020) Hydroxychloroquine and azithromycin as a treatment of COVID-19: results of an open- label non-randomized clinical trial. J Antimicrob Agents. https://doi.org/10.1016/j.ijantimicag.2020.105949

Gómez N, Carrillo C, Salinas J et al (1998) Expression of immunogenic glycoprotein $\mathrm{S}$ polypeptides from transmissible 
gastroenteritis coronavirus in transgenic plants. Virology 249:352-358. https://doi.org/10.1006/viro.1998.9315

Gómez N, Wigdorovitz A, Castañón S et al (2000) Oral immunogenicity of the plant derived spike protein from swine-transmissible gastroenteritis coronavirus. Arch Virol 145:1725-1732. https://doi.org/10.1007/s007050070087

Harrison C (2020) Coronavirus puts drug repurposing on the fast track. Nat Biotechnol 38:379-381. https://doi.org/10.1038/d41587-02000003-1

Ho TY, Wu SL, Chen JC et al (2007) Emodin blocks the SARS coronavirus spike protein and angiotensin-converting enzyme 2 interaction. Antivir Res 74:92-101. https://doi.org/10.1016/j.antiv iral.2006.04.014

Hsieh LE, Lin CN, Su BL et al (2010) Synergistic antiviral effect of Galanthus nivalis agglutinin and nelfinavir against feline coronavirus. Antivir Res 88:25-30. https://doi.org/10.1016/j.antiv iral.2010.06.010

Kayser O (2018) Ethnobotany and medicinal plant biotechnology: from tradition to modern aspects of drug development. Planta Med 84:834-838. https://doi.org/10.1055/a-0631-3876

Keyaerts E, Vijgen L, Pannecouque C et al (2007) Plant lectins are potent inhibitors of coronaviruses by interfering with two targets in the viral replication cycle. Antivir Res 75:179-187. https://doi. org/10.1016/j.antiviral.2007.03.003

Khosroushahi AY, Valizadeh M, Ghasempour A et al (2006) Improved Taxol production by combination of inducing factors in suspension cell culture of Taxus baccata. Cell Biol Int 30:262-269. https ://doi.org/10.1016/j.cellbi.2005.11.004

Lau TF, Leung PC, Wong ELY et al (2005) Using herbal medicine as a means of prevention experience during the SARS crisis. Am J Chin Med 33:345-356. https://doi.org/10.1142/S0192415X0 5002965

Li G, De Clercq E (2020) Therapeutic options for the 2019 novel coronavirus (2019-nCoV). Nat Rev Drug Discov 19:149-150. https:// doi.org/10.1038/d41573-020-00016-0

Li SY, Chen C, Zhang HQ et al (2005) Identification of natural compounds with antiviral activities against SARS-associated coronavirus. Antivir Res 67:18-23. https://doi.org/10.1016/j.antiv iral.2005.02.007

Li HY, Ramalingam S, Chye ML (2006) Accumulation of recombinant SARS-CoV spike protein in plant cytosol and chloroplasts indicate potential for development of plant-derived oral vaccines. Exp Biol Med 231:1346-1352. https://doi.org/10.1177/1535370206 23100808

Lin CW, Tsai FJ, Tsai CH et al (2005) Anti-SARS coronavirus 3C-like protease effects of Isatis indigotica root and plant-derived phenolic compounds. Antivir Res 68:36-42. https://doi.org/10.1016/j. antiviral.2005.07.002

Lin SC, Ho CT, Chuo WH et al (2017) Effective inhibition of MERSCoV infection by resveratrol. BMC Infect Dis 17:144. https://doi. org/10.1186/s12879-017-2253-8

MPIKG (2020) Max Planck Institute for colloids and interfaces press release. https://www.mpikg.mpg.de/6288044/news_publicatio n_14663263_transferred?c=132305. Accessed 10 May 2020

O'Connor SE (2015) Engineering of secondary metabolism. Annu Rev Genet 49:71-94. https://doi.org/10.1146/annurev-genet-12021 3-092053

Park HR, Yoon H, Kim MK et al (2012) Synthesis and antiviral evaluation of 7-O-arylmethylquercetin derivatives against SARS-associated coronavirus (SCV) and hepatitis $\mathrm{C}$ virus (HCV). Arch Pharm Res 35:77-85. https://doi.org/10.1007/s12272-012-0108-9

PIB (2020) Press Information Bureau, India. https://pib.gov.in/newsite/ PrintRelease. aspx? relid=200005. Accessed 10 May 2020

Pogrebnyak N, Golovkin M, Andrianov V et al (2005) Severe acute respiratory syndrome (SARS) $\mathrm{S}$ protein production in plants: development of recombinant vaccine. Proc Natl Acad Sci USA 102:9062-9067. https://doi.org/10.1073/pnas.0503760102
Rosales-Mendoza S (2020) Will plant-made biopharmaceuticals play a role in the fight against COVID-19? Expert Opin Biol Ther. https ://doi.org/10.1080/14712598.2020.1752177

Rothan HA, Stone S, Natekar J et al (2020) The FDA-approved gold drug Auranofin inhibits novel coronavirus (SARS-COV-2) replication and attenuates inflammation in human cells. bioRxiv. https ://doi.org/10.1101/2020.04.14.041228

Ryu YB, Jeong HJ, Kim JH et al (2010) Biflavonoids from Torreya nucifera displaying SARS-CoV 3CLpro inhibition. Bioorganic Med Chem 18:7940-7947. https://doi.org/10.1016/j. bmc.2010.09.035

Shoseyov O, Posen Y, Grynspan F (2013) Human collagen produced in plants more than just another molecule. Bioengineered. https ://doi.org/10.4161/bioe.26002

Sivaraman D, Pradeep PS (2020) Revealing anti-viral potential of bioactive therapeutics targeting SARS-CoV2-polymerase (RdRp) in combating COVID-19: molecular investigation on indian traditional medicines. Preprints. https://doi.org/10.20944/preprints2 02003.0450.v1

Takeyama N, Kiyono H, Yuki Y (2015) Plant-based vaccines for animals and humans: recent advances in technology and clinical trials. Ther Adv Vaccines 3:139-154. https://doi.org/10.1177/20510 13615613272

Thileepan T, Prasad VM (2018) Literature review of suram (fever) in siddha medicine. J Res Tradit Med 4:21-25. https://doi. org/10.5455/jrtm.2018/298118

Vellingiri B, Jayaramayya K, Iyer M et al (2020) COVID-19: a promising cure for the global panic. Sci Total Environ 725:138277. https ://doi.org/10.1016/j.scitotenv.2020.138277

Wang M, Cao R, Zhang L et al (2020) Remdesivir and chloroquine effectively inhibit the recently emerged novel coronavirus (2019$\mathrm{nCoV}$ ) in vitro. Cell Res 30:269-271. https://doi.org/10.1038/ s41422-020-0282-0

Wu CY, Jan JT, Ma SH et al (2004) Small molecules targeting severe acute respiratory syndrome human coronavirus. Proc Natl Acad Sci USA 101:10012-10017. https://doi.org/10.1073/pnas.04035 96101

Xing J, Shankar R, Drelich A et al (2020) Reversal of infected host gene expression identifies repurposed drug candidates for COVID-19. bioRxiv. https://doi.org/10.1101/2020.04.07.030734

Yang CW, Lee YZ, Kang IJ et al (2010) Identification of phenanthroindolizines and phenanthroquinolizidines as novel potent anti-coronaviral agents for porcine enteropathogenic coronavirus transmissible gastroenteritis virus and human severe acute respiratory syndrome coronavirus. Antivir Res 88:160-168. https://doi. org/10.1016/j.antiviral.2010.08.009

Yang Y, Islam MS, Wang J et al (2020) Traditional chinese medicine in the treatment of patients infected with 2019-new coronavirus (SARS-CoV-2): a review and perspective. Int J Biol Sci 16:17081717. https://doi.org/10.7150/ijbs. 45538

Yi L, Li Z, Yuan K et al (2004) Small molecules blocking the entry of severe acute respiratory syndrome coronavirus into host cells. J Virol 78:11334-11339. https://doi.org/10.1128/jvi.78.20.11334 $-11339.2004$

Yu M, Lee J, Moo J et al (2020) Identification of myricetin and scutellarein as novel chemical inhibitors of the SARS coronavirus helicase, nsP13. Bioorganic Med Chem Lett 22:4049-4054

Zhong N (2004) Management and prevention of SARS in China. Philos Trans R Soc B Biol Sci 359:1115-1116. https://doi.org/10.1098/ rstb.2004.1491

Publisher's Note Springer Nature remains neutral with regard to jurisdictional claims in published maps and institutional affiliations. 